\title{
Elevated Free Radical Products in the Cerebrospinal Fluid of VLBW Infants with Cerebral White Matter Injury
}

\author{
TERRIE INDER, TESSA MOCATTA, BRIAN DARLOW, CAROLE SPENCER, \\ JOSEPH J. VOLPE, AND CHRISTINE WINTERBOURN \\ The Murdoch Children's Research Institute and Howard Florey Institute and Royal Women's and Royal \\ Children's Hospital [T.I.], Melbourne, Australia; Department of Pediatrics [B.D., C.S.], Department of \\ Pathology [T.M., C.W.], Christchurch School of Medicine and Health Sciences, Christchurch, New \\ Zealand; Department of Neurology, Children's Hospital and Harvard Medical School [T.I., J.J.V.], \\ Boston, Massachusetts
}

\begin{abstract}
Free radical mediated cellular injury has been hypothesized to play a key role in the pathogenesis of white matter injury in the premature infant, although direct evidence is lacking. Between April 1999 and May 2001, 22 very low birthweight infants, 30 term infants, and 17 adults had samples of cerebrospinal fluid (CSF) collected for clinical indications. Only CSF samples without any evidence of meningeal inflammation were analyzed for the levels of the lipid peroxidation products, 8-isoprostane and malondialdehyde (MDA), and protein carbonyls as a measure of protein oxidation. Chlorotyrosine was monitored as a measure of neutrophil oxidative activity. In the premature infants with subsequent evidence of white matter injury on magnetic resonance imaging at term, there was a significant elevation in the CSF level of protein carbonyls in comparison with the level in healthy premature infants, term infants, and adult controls (all $p<$ 0.001 ). A significant difference in the levels of the lipid peroxidation products, 8-isoprostane and MDA, was apparent between
\end{abstract}

\section{ABSTRACT}

premature infants with white matter injury and adult controls (isoprostanes $p=0.02$, MDA $p=0.014$ ). There was a trend toward higher levels of 8 -isoprostane in the premature infants with white matter injury in comparison with those without white matter injury $(p=0.08)$, with 5 of the 14 infants with white matter injury having levels that were more than 10 -fold higher than the top of the adult range. There was no significant difference in the level of chlorotyrosines among any of the groups. These preliminary data provide evidence of an association of elevated oxidative products during the evolution of white matter injury in the human premature infant. (Pediatr Res 52: 213-218, 2002)
CSF, Cerebrospinal fluid
MDA, Malondialdehyde
MRI, Magnetic resonance imaging

Abbreviations
With improved survival of the extremely premature infant, there is an increasing recognition of long-term adverse neurodevelopmental outcome, with up to $50 \%$ of these infants later experiencing significant neurodevelopmental disability (1). Periventricular leukomalacia (PVL) in the premature infant is a distinctive lesion of cerebral white matter associated with much of this adverse neurologic outcome. The pathogenesis of cerebral white matter injury in the premature infant is not entirely clear, although ischemia-reperfusion and infection/

Received October 22, 2001; accepted March 4, 2002.

Correspondence and reprint requests: Terrie Inder, Murdoch Children's Research Institute and Howard Florey Institute, Royal Women's and Royal Children's Hospital, 2nd Floor, Royal Children's Hospital, Flemington Road, Parkville VIC 3052, Australia; e-mail: indert@cryptic.rch.unimelb.edu.au

Supported by grants from the Neurological Foundation of New Zealand, Health Research Council of New Zealand, and Lottery Health of New Zealand.

DOI: 10.1023/01.PDR.0000020088.11295.13 inflammation appear to be important (2). The unique nature of this neuropathological lesion in the premature infant is hypothesized to relate in part to an exquisite vulnerability of the immature oligodendrocyte to free radical damage (2-5). In two model systems of free radical accumulation, the early differentiating oligodendrocyte has been shown to be exquisitely vulnerable to free radical attack (2-5). The free radical vulnerability appears to be present only during this specific cell stage of oligodendrocyte development. Moreover, this immature form, the so-called preoligodendrocyte, has been shown recently to account for $90 \%$ of the total population of oligodendrocytes in cerebral white matter of infants under the gestational age of $31 \mathrm{wk}(6)$, the period when the premature infant is most at risk for white matter injury.

Although free radical mediated cellular injury has been proposed as a key pathogenetic factor in cerebral white matter injury in the premature infant $(2-4)$, direct evidence is lacking. 
Because free radicals are too short-lived to be detected directly in clinical samples, indirect biomarkers of reactive oxidant production are measured. Biomarkers of lipid peroxidation and protein oxidation are available. To assess lipid peroxidation in this study, we have measured the $\mathrm{F}_{2}$-isoprostane, 8-isoprostane (8-isoprostaglandin $\mathrm{F}_{2 \alpha}$ ). Isoprostanes are stable oxidation products of arachidonic acid that are formed specifically as a result of lipid peroxidation $(7,8)$. They are elevated in a number of disorders in which free radicals are implicated $(8-10)$ and are considered to be a highly reliable index of lipid peroxidation. We have also measured MDA, which is a less specific and discriminatory biomarker of lipid peroxidation than 8 isoprostanes. However, when the MDA assay has included HPLC separation of the products, it has been informative in a number of studies (11-14). Protein carbonyls, particularly when measured by ELISA, provide a sensitive measure of protein oxidation (15-17). A variety of oxidative mechanisms generate carbonyl groups directly on proteins, or these groups can arise through covalent attachment of aldehyde products of lipid peroxidation (16-19). Elevated protein carbonyls have been found in association with oxidative stress (20-23). In this study, we have also monitored chlorotyrosine, which is produced by the modification of the amino acid tyrosine by hypochlorous acid. Hypochlorous acid is a unique product of myeloperoxidase and is therefore a specific marker of oxidation due to inflammatory cells (neutrophils and monocytes) that contain this enzyme (24). In combination, these assays can provide important insights concerning associations of elevated reactive oxidative species with disease states.

The aim of this study was to evaluate the relationship between the levels of lipid and protein oxidation products in the CSF of premature infants and the presence of white matter injury identified at term by MRI. We hypothesized that infants who exhibited white matter injury would have elevated CSF levels of the oxidative markers when compared with infants who did not exhibit white matter injury.

\section{METHODS}

\section{Study Population}

This longitudinal cohort study was derived from a population that comprised any infants admitted to the special care baby unit or the neonatal intensive care unit at Christchurch Women's Hospital, Christchurch, New Zealand between April 1999 and May 2001 who underwent a lumbar puncture study for clinical indications. The infants included in the analysis for this study were (1) term infants, greater than $36 \mathrm{wk}$ gestational age at birth and (2) premature infants with birthweight less than $1500 \mathrm{~g}$ or gestational age equal to or less than $32 \mathrm{wk}$. Samples collected from adult control subjects at the time of elective spinal anesthesia were also analyzed.

Informed written consent was obtained from the adult subjects and the parents of all infants in this study. The Institutional Review Board of the Christchurch Women's Hospital approved this study.

Clinical information. Information derived from the clinical setting as well as from the results of CSF examination, including CSF culture, cell count, protein, and glucose, was collected to identify proven or probable meningitis. Samples were excluded from further analysis if there was any evidence of meningeal inflammation, for example, an elevated CSF white cell count ( $>5 \mathrm{WBC}$ correcting for red cell count by 1:500) or positive CSF culture or bacterial antigen testing. In addition, infants with cerebral dysgenesis were excluded. For all infants enrolled, there was an extensive review of the records of the pregnancy, birth history, and neonatal course, including respiratory, cardiovascular and nutritional parameters, and the results of cranial ultrasound scans, which were performed routinely in the first $72 \mathrm{~h}$ of life, and again at least at 7 and $42 \mathrm{~d}$ of life.

\section{Measurement of Oxidation Products}

An additional $1 \mathrm{~mL}$ sample of CSF was taken at the time of the clinically indicated lumbar puncture studies. All samples were centrifuged within an hour of collection, separated and stored at $-80^{\circ} \mathrm{C}$. Protein carbonyl concentrations were determined by ELISA (17) with the following modification: protein $(5 \mu \mathrm{g}$ in $5 \mu \mathrm{L})$ was derivatized with $2.5 \mathrm{mM}$ dinitrophenylhydrazine $(15 \mu \mathrm{L})$ and then diluted to $1 \mathrm{~mL}$ in PBS. The assay was performed on $200 \mu \mathrm{L}$ aliquots of this solution added to each well. Chlorotyrosine/tyrosine ratios were assayed on hydrolysates from $40 \mu \mathrm{g}$ protein by stable isotope dilution gas chromatography/mass spectroscopy (25). 8-Isoprostane levels in $50 \mu \mathrm{L}$ CSF samples were determined using an ELISA kit (Cayman Chemicals, Ann Arbor, MI, USA). MDA was measured in $20 \mu \mathrm{L} \mathrm{CSF}$ after derivatization with thiobarbituric acid by HPLC with fluorescence detection (26).

\section{Magnetic Resonance Imaging and Definition of White Matter Injury}

MRI was undertaken as part of a research protocol during the week of the infant's expected date of delivery (27). MRI assessment of the cerebral white matter was defined qualitatively as normal or as exhibiting evidence of white matter injury, the latter based on a modified qualitative assessment scoring (28). To identify any relationship between the different forms of white matter injury and the CSF levels of oxidative markers, the premature infants with any evidence of white matter injury were further subdivided into groups on the basis of the presence of (1) cystic white matter injury, (2) signal abnormality in the periventricular white matter, or (3) isolated ventriculomegaly without cysts or white matter signal abnormality. Representative examples are shown in Figure 1.

\section{Statistical Analysis}

Statistical analyses were performed with SyStat and SPSS for Windows (SPSS Inc, Chicago, IL, USA). For comparison of the measures of oxidative products between the four groups, tests of significance were based on chi-square test of independence for dichotomous measures and one-way analysis of variance for continuous measures. Nonparametric analyses were undertaken with either Kruskall-Wallis or for ordered categories between two groups. Contrast was achieved with the Mann-Whitney U test. Log transformation of the level of 

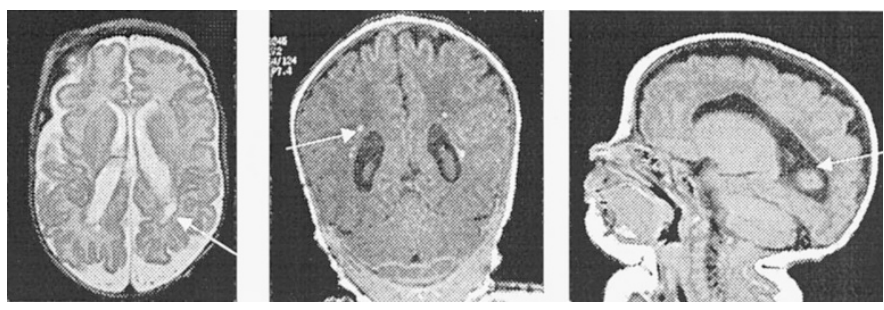

Figure 1. Representative magnetic resonance images of three different premature infants with white matter injury to illustrate the three classifications. Left image, axial T2-weighted image. Cystic white matter (arrow) injury with ventriculomegaly. Middle image, SPGR coronal image. Signal abnormality (arrow) in periventricular white matter with ventriculomegaly. Right image, sagittal image. Isolated ventriculomegaly (arrow) without cysts or white matter signal abnormality.

8-isoprostane was undertaken before regressional analysis to allow approximation to normal distribution of the data.

\section{RESULTS}

\section{Population Characteristics}

Eighty-eight samples were collected from 30 term infants and 30 premature infants. Eight premature infants and four term infants, many with repeated samples, were excluded because of the presence of meningeal inflammation $(n=10)$ or cerebral dysgenesis $(n=2)$. Thus, after exclusion of these infants, the remaining population consisted of 22 premature infants and 26 term infants who had only a single CSF sample available to be analyzed. Seventeen adult control CSF samples also were analyzed.

The 22 premature infants had a mean gestational age of 27.4 wk (range 23-32 wk) and a mean birthweight of $1090 \mathrm{~g}$ (range $560-1520 \mathrm{~g}$ ). Of these 22 infants, 6 had intraventricular hemorrhage and 13 had persisting oxygen requirements at $36 \mathrm{wk}$ post conceptual age. Fourteen of the 22 had evidence of white matter injury on their MRI scan at term. The injury was identified as cystic white matter injury with ventriculomegaly in two infants, periventricular signal abnormality with ventriculomegaly in four infants, and isolated ventriculomegaly in eight infants (Fig. 1).

The CSF samples were taken at a similar postnatal age in the premature infants with white matter injury [mean \pm SEM $27 \pm$ $8 \mathrm{~d}(n=14)]$; and in those with no white matter injury [22 \pm $4.7 \mathrm{~d}(n=8)]$. The CSF samples from the term infants were acquired at the earlier postnatal age of $4.0 \pm 1.1 \mathrm{~d}$.

\section{Relationship of CSF Oxidative Markers to White Matter Injury}

Protein carbonyl levels. Premature infants with evidence of white matter injury at term had a highly significant elevation in CSF protein carbonyl levels (generally 2-fold) in comparison with the premature infants without white matter injury, the term infants, and the adult subjects (Fig. 2, Table 1, $p<0.001$ for all comparisons, Kruskal-Wallis). Posthoc analysis showed that there were highly statistically significant differences between the premature infants with white matter injury in comparison with each of the other groups (Kruskal-Wallis, $p<$ 0.001 for all comparisons).
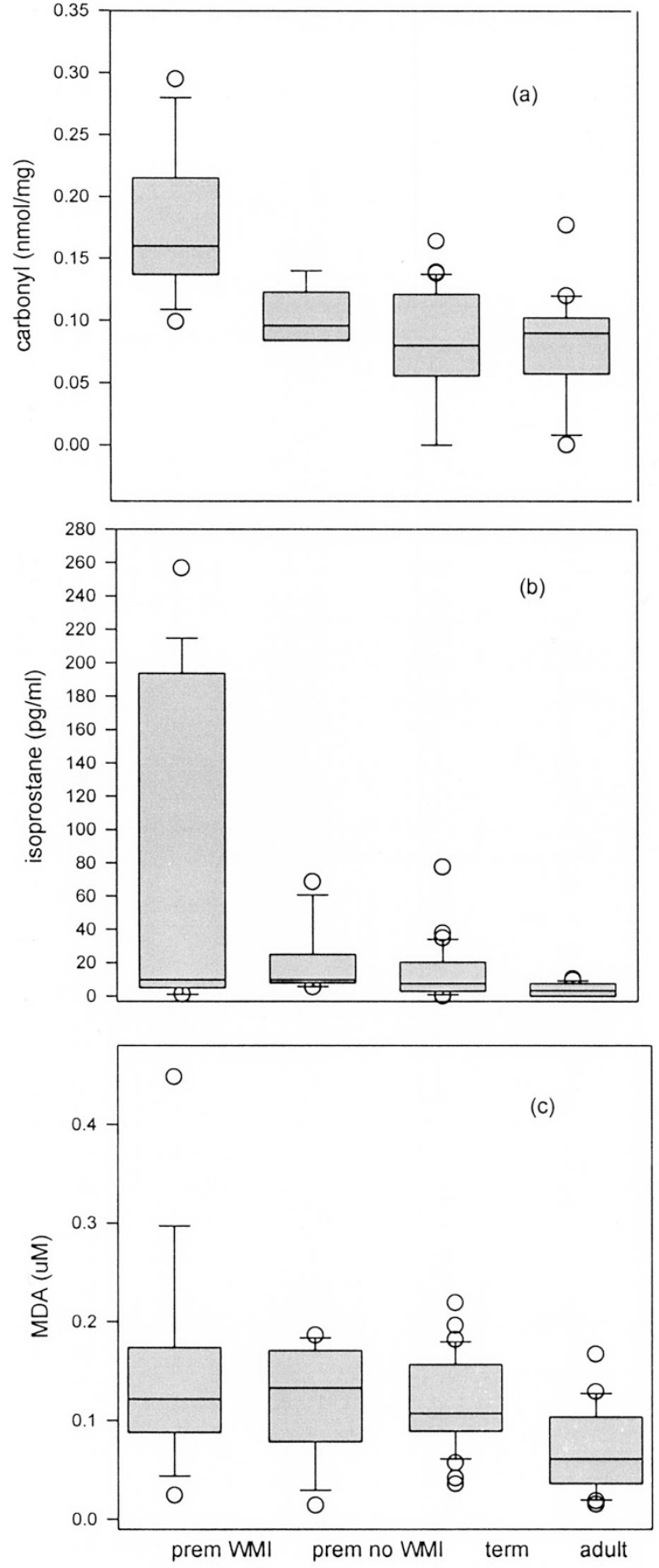

Figure 2. Levels of markers of lipid and protein oxidation in CSF of premature infants with white matter injury (prem WMI), premature infants without white matter injury (prem no WMI), term infants, and adults. Values shown are median levels $(25$ th/75th box; 10th/90th error bars and individual outliers) of protein carbonyls (upper graph); isoprostanes (middle graph), and MDA (lower graph).

Lipid peroxidation measures. Analysis of the CSF levels of the two markers of lipid peroxidation revealed a significant difference in levels of both among the four groups (KruskalWallis MDA, $p=0.02 ; 8$-isoprostane, $p=0.04$ ). Posthoc analysis showed that the statistically significant difference lay between the premature infants with white matter injury in 
comparison with the adult subjects (Kruskal-Wallis, MDA $p=$ 0.01 ; isoprostanes $p=0.02$ ). There was no significant difference between the two groups of premature infants for MDA. However, there was a trend toward an elevation in the levels of 8 -isoprostane in the premature infants with white matter injury in comparison with those without white matter injury (KruskalWallis, $p=0.08$ ). Inspection of the individual data showed two clusters in the white matter injury group. Five samples had 8 -isoprostane levels at least 10-fold higher than the top of the adult range, whereas the other nine levels fell well within this range. The CSF levels of chlorotyrosine were not elevated in the premature infants with white matter injury (Table 1).

A relationship could be discerned between the category of white matter injury and the levels of isoprostanes. The levels of isoprostanes were significantly higher in the premature infants with cystic white matter injury in comparison with the levels in the other two groups, i.e. premature infants with signal abnormality or isolated ventriculomegaly [median values (range) cystic white matter injury $230(204-256, n=2)$ ]; signal abnormality $84(9.8-344, n=3)$; isolated ventriculomegaly 6 $(1-9, n=8)$ Kruskal-Wallis $p=0.008)$. There was no significant difference in the levels of protein carbonyls and MDA between these groups of infants with white matter injury.

\section{Relationship of Oxidative Markers to Timing of Sample}

The levels of each of the oxidative products were also analyzed as a function of the timing of the sample. Levels of isoprostanes were found to be highly elevated (10-fold upper limit of adult range) only in the first $21 \mathrm{~d}$ of life. The levels of isoprostanes in this period were significantly higher in the infants with white matter injury compared with the levels in those without white matter injury ( $p=0.02$, Kruskall-Wallis). The protein carbonyl levels appeared to remain elevated for a more prolonged period of postnatal age.

\section{Correlation of Lipid and Protein Oxidative Markers}

Linear regressional analysis of the relationship of the measures of oxidative products in all CSF samples from all the patient groups revealed a strong correlation between protein carbonyls and MDA $(r=0.66, \mathrm{~F}=48.23, p<0.001)$. Because of the nonlinear distribution of the levels of isoprostanes, $\log$ transformation was undertaken before regressional correlation. There was a weaker correlation between the levels of isoprostanes and MDA (log-isoprostanes:MDA $r=0.12, p$ $=0.12$ ) or protein carbonyls (log-isoprostanes:protein carbonyl $r=0.19, p=0.10$ ).

\section{DISCUSSION}

This study is the first to document an elevation in the early postnatal period in measures of free radical products in the CSF of premature infants with cerebral white matter injury later apparent on MRI at term. The reliability of these findings is strengthened by the elevations in measures of both lipid and protein oxidation products determined by newer and more specific assays for free radical activity. These data provide evidence of an association of elevated reactive oxidative species with cerebral white matter injury in the premature infant.

There are clear limitations to this study, principally our small sample size, the inability to time the occurrence of the cerebral injury, the variation in the timing of the CSF samples, and our definition of cerebral white matter injury. However, despite these limitations, the data show a correlation between the levels of oxidative markers and the presence of white matter injury.

Isoprostanes are regarded as specific markers of free radical reaction with lipids. Isoprostanes are the products of free radical damage to arachidonic acid (AA20:4 $\square$ 6). They are formed while this fatty acid is esterified to lipid and are released upon lipid hydrolysis $(29,30)$. The 8 -isoprostane ELISA measures predominantly the FFA form. 8-Isoprostanes measured in our study could have been formed either within the CSF or within cells in the CNS and released after hydrolysis. In neurologic diseases, F2-isoprostane levels have been found to be elevated in the CSF from patients with probable Alzheimer's disease early in the course of their dementia (10) and in Huntington's disease (9). 8-Isoprostane was highly elevated in five CSF samples from the 14 infants with white matter injury, with a clear increase in those with the more severe cystic white matter injury. The lack of an elevation in isoprostanes level in some infants with white matter injury could be a consequence of the timing of the insult in relation to the timing of the sample, an issue over which we had no control. Isoprostanes are known to have a short half life (31) in comparison with protein carbonyls, which persist as long as the proteins on which they are situated. Alternatively, the lack of an elevation in isoprostanes in some infants with white matter injury could reflect the nature of the white matter injury (31). Our findings of a significant elevation in the level of isoprostanes in the premature infants with cystic white matter injury with ventriculomegaly in comparison with the premature infants with the less severe forms of white matter injury, i.e. white matter signal abnormality or isolated ventriculomegaly, is noteworthy. However, our numbers are too small to draw

Table 1. Levels of markers of lipid and protein oxidation in CSF of premature infants with white matter injury (prem WMI), premature infants without white matter injury (prem no WMI), term infants, and adults

\begin{tabular}{|c|c|c|c|c|c|}
\hline & $\begin{array}{c}\text { Prem WMI } \\
(n=14)\end{array}$ & $\begin{array}{l}\text { Prem no WMI } \\
(n=8)\end{array}$ & $\begin{array}{c}\text { Term } \\
(n=26)\end{array}$ & $\begin{array}{c}\text { Adult } \\
(n=17)\end{array}$ & $\begin{array}{c}p \text { value } \\
\text { Kruskall-Wallis }\end{array}$ \\
\hline Isoprostane (pg/mL) & $88.6 \pm 33.4$ & $17.5 \pm 7.8$ & $10.4 \pm 2.4$ & $4.2 \pm 0.9$ & 0.04 \\
\hline MDA $(\mu \mathrm{mol})$ & $0.15 \pm 0.03$ & $0.13 \pm 0.03$ & $0.13 \pm 0.01$ & $0.07 \pm 0.05$ & 0.02 \\
\hline Protein carbonyl (nmol/mg total protein) & $0.18 \pm 0.02$ & $0.09 \pm 0.01$ & $0.07 \pm 0.01$ & $0.08 \pm 0.01$ & $<0.001$ \\
\hline Chlorotyrosine/tyrosine (CT/1000 Tyr) & $0.014 \pm 0.01$ & $0.009 \pm 0.003$ & $0.009 \pm 0.005$ & $0.015 \pm 0.007$ & NS \\
\hline
\end{tabular}

Values shown are mean levels \pm SEM. 
firm conclusions, and further studies are warranted to understand these relationships.

In contrast to CSF levels of isoprostane, no clear relationship of CSF levels of MDA and severity of white matter injury emerged, perhaps reflecting the limitations of this lipid peroxidation marker. Of the measures of lipid peroxidation, MDA is a frequently used measure, but because of the wide variety of techniques used, this measure must often be interpreted cautiously (11-14). The HPLC methodology with fluorescence detection (26) used in this study is among the most reliable methodologies for the detection of this sensitive though nonspecific marker of lipid peroxidation.

We found that CSF levels of protein carbonyls were consistently about 2-fold higher in the infants with white matter injury. Elevated protein carbonyls have been measured in brain tissue from Alzheimer patients, with recognition of selectively modified proteins (23). The specific modification giving rise to protein carbonyls in the CSF in our premature infants, and the proteins that are modified, are not known. Although lipid peroxidation products can bind and contribute to protein carbonyl measurements (19), direct oxidation to give carbonyls appears to be one of the first changes observed with relatively low oxidative stress (21).

Free radical mediated injury has been hypothesized to be the final common pathway to oligodendroglial cell death in cerebral white matter injury in the premature infant (2). Experimental and neuropathological data suggest a maturationdependent window of vulnerability of oligodendroglial precursors to free radical attack $(3,4)$, perhaps thereby explaining in part the unique topography and timing of this pattern of brain injury in the premature infant. The early differentiating oligodendroglial cell, the preoligodendrocyte, is particularly vulnerable to free radical mediated cellular injury $(3,4)$ and accounts for almost all of white matter oligodendrocytes in the preterm brain below $31 \mathrm{wk}$ gestation, the time period of highest risk for PVL (6). The lipid composition of the oligodendroglial cell may further increase its vulnerability to oxidative injury (32). Macrophages may also have increased neurotoxic action on white matter under conditions of oxidative stress (33). In addition, human immature white matter appears to have a reduced antioxidant defense system. Houdou et al. (34) demonstrated a delay in catalase expression in white matter glial cells until approximately $31 \mathrm{wk}$ of gestation and thereafter only a slow development in a gradient from deep to superficial white matter. Therefore, the capacity to detoxify hydrogen peroxide may be limited early in oligodendroglial development. However, despite these observations, before this report there was little evidence of a role for free radicals in white matter injury in the human premature infant.

Excessive free radical production may occur by a wide variety of mechanisms, many of which are commonly implicated in the pathogenesis of PVL. These mechanisms include ischemia-reperfusion (35-37), inflammation, and infection (38, 39). The CSF samples analyzed in this series had no evidence of meningeal inflammation or infection. Moreover, the CSF levels of chlorotyrosine were not elevated in the infants with white matter injury. Chlorotyrosine is generated by the modification of tyrosine by hypochlorous acid and provides a marker of neutrophil oxidant activity (24). We have documented elevated CSF chlorotyrosine in an infant with meningitis (39). The lack of any significant elevation of chlorotyrosine levels in the premature infants with white matter injury is consistent with a paucity of neutrophils observed neuropathologically in PVL (40) and suggests that neutrophil activation did not contribute to the oxidative stress. This study was not designed to assess whether cerebral ischemia-reperfusion could have been the cause of oxidative injury in our cases.

The analysis of the CSF levels of oxidative markers as a function of the age at sampling (Fig. 3) reveals that premature infants with cerebral white matter injury had elevations in isoprostane levels only in the first $2 \mathrm{wk}$ of life. In the first $21 \mathrm{~d}$, the levels of isoprostanes were significantly higher in the infants with white matter injury in contrast with the levels in those without such injury. In contrast, protein carbonyl levels remained elevated for a longer period of time. This may reflect a more delayed CSF clearance of this protein oxidative product. Further studies are warranted to investigate the relationship of the levels of these oxidative markers to the timing and the nature of cerebral white matter injury in the premature infant.
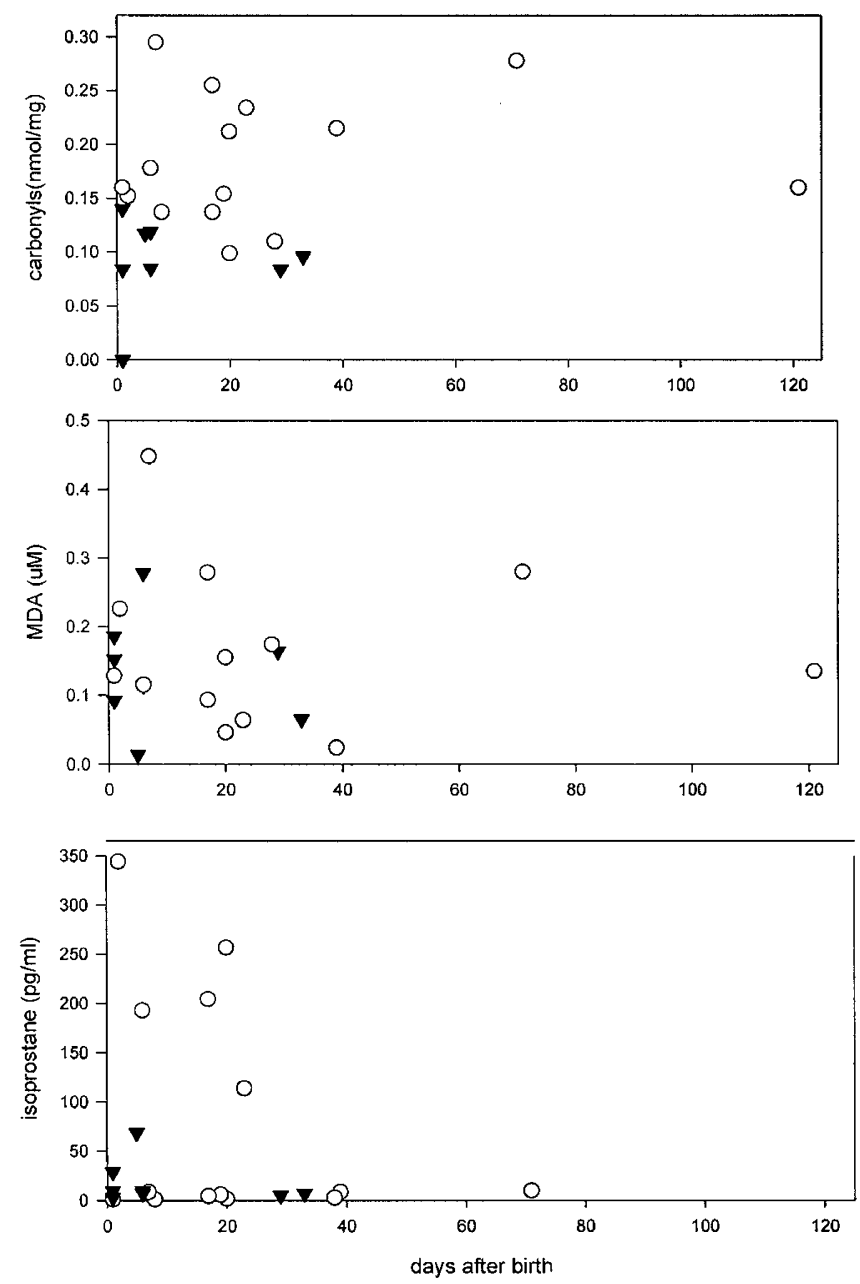

Figure 3. The relationship of the level of protein carbonyls (upper graph), MDA (middle graph) and isoprostanes (lower graph) to the timing of CSF samples in the premature infants with white matter injury (open circles) and the premature infants without white matter injury (closed triangles) 
In conclusion, this study documents an association between elevations in the CSF levels of oxidative products in premature infants with cerebral white matter injury. These markers of free radical attack suggest that the generation of reactive oxygen species is important in pathogenesis. Although these findings require confirmation and amplification with a larger sample size and more accurate timing of white matter injury, the data provide insight into potential pathogenic mechanisms and perhaps, thereby, potential protective therapies for PVL in premature infants.

Acknowledgments. We are grateful to Dr. R. Senthilmohan for performing the chlorotyrosine assays and to Dr. A.J. Kettle for his input in establishing the methodology.

\section{REFERENCES}

1. Wood NS, Marlow N, Costeloe K Gibson AT 2000 Neurologic and developmental disability after extremely preterm birth. N Engl J Med 343:378-384

2. Volpe, JJ 2001 Neurology of the Newborn, 4th Ed. WB Saunders, Philadelphia

3. Yonezawa M, Back SA, Gan X, Rosenberg PA, Volpe JJ 1996 Cystine deprivation induces oligodendroglial death: rescue by free radical scavengers and by a diffuse glial factor. J Neurochem 67: 566-573

4. Back SA, Gan X, Li Y, Rosenberg PR, Volpe JJ 1998 Maturation-dependent vulnerability of oligodendrocytes to oxidative stress-induced death caused by glutathione depletion. J Neurosci 18:6241-6253

5. Oka A, Belliveau MJ, Rosenberg PA, Volpe JJ 1993 Vulnerability of oligodendroglia to glutamate: pharmacology, mechanisms and prevention. J Neurosci 13:1441-1453

6. Back SA, Luo NL, Borenstein NS, Levine JM, Volpe JJ, Kinney HC 2001 Late oligodendrocyte progenitors coincide with the developmental window of vulnerability for human perinatal white matter injury. J Neurosci 21:1302-1312

7. Roberts LJ, Morrow JD 2000 Measurement of F(2)-isoprostanes as an index of oxidative stress in vivo. Free Radic Biol Med 28:505-513

8. Morrow JD, Roberts LJ 1997 The isoprostanes: current knowledge and directions for future research. Biochem Pharmacol 51:1-9

9. Montine TJ, Beal MF, Robertson D, Cudkowicz ME, Biaggioni I, O’Donnell H, Zachert WE, Roberts LJ, Morrow JD 1999 Cerebrospinal levels of F2-isoprostanes, specific markers of lipid peroxidation are elevated in Huntington's disease patients. Neurology 52:1104-1105

10. Montine TJ, Markesbery WR, Morrow JD, Roberts LJ 1998 Cerebrospinal fluid F2-isoprostanes are increased in Alzheimer's disease. Ann Neurol 44:410-413

11. Draper HH, Hadley M 1990 Malondialdehyde determination as an index of lipid peroxidation. Methods Enzymol 186:421-431

12. Slater TF 1984 Overview of methods used for detecting lipid peroxidation. Methods Enzymol 105:283-292

13. Halliwell B, Chirico S 1993 Lipid peroxidation: its mechanism, measurement and significance. Am J Clin Nutr 57:715S-725S

14. Janero DR 1990 Malondialdehyde and thiobarbituric acid-reactivity as diagnostic indices of lipid peroxidation and peroxidative tissue injury. Free Radic Biol Med 9:515-540

15. Gladstone IMJ, Levine RL 1994 Oxidation of proteins in neonatal lungs. Pediatrics 93:764-768

16. Shacter E, Williams JA, Lim M, Levine RL 1994 Differential susceptibility of plasma proteins to oxidative modification: examination by western blot immunoassay. Free Radic Biol Med 17:429-437

17. Buss H, Chan TP, Sluis KB, Domigan NM, Winterbourn CC 1997 Protein carbonyl measurement: a sensitive ELISA method. Free Rad Biol Med 23:361-366
18. Levine RL, Williams ER, Sadtman ER, Shacter E 1994 Carbonyl assays for determination of oxidatively modified proteins. Methods Enzymol 233:346-357

19. Blakeman DP, Ryan TP, Jolly RA, Petry TW 1995 Diquat dependent protein carbonyl formation: identification of lipid-dependent and lipid-independent pathways. Biochem Pharmacol 50:929-935

20. Winterbourn CC, Buss IH, Chan TP, Plank LD, Clark MA, Windsor JA 2000 Protein carbonyl measurements show evidence of early oxidative stress in critically ill patients. Crit Care Med 28:143-149

21. Ciolino HP, Levine RL 1997 Modification of proteins in endothelial cell death during oxidative stress. Free Rad Biol Med 22:1277-1282

22. Buss IH, Darlow BA, Winterbourn CC 2000 Elevated protein carbonyls, lipid peroxidation products and myeloperoxidase in tracheal aspirates from premature infants. Pediatr Res 47:640-645

23. Aksenov MY, Aksenova MV, Butterfield DA, Geddes JW, Markesbery WR 2001 Protein oxidation in the brain in Alzheimer's disease. Neuroscience 10:373-383

24. Winterbourn CC, Kettle AJ 2000 Biomarkers of myeloperoxidase-derived hypochlorous acid. Free Radic Biol Med 29:403-409

25. Chapman AL, Senthilmohan R, Winterbourn CC, Kettle AJ 2000 Comparison of mono- and dichlorinated tyrosines with carbonyls for detection of hypochlorous acid modified proteins. Arch Biochem Biophys 377:95-100

26. Young IS, Trimble ER 1991 Measurement of malondialdehyde in plasma by high performance liquid chromatography with fluorimetric detection. Ann Clin Biochem 28:504-508

27. Inder TE, Huppi PS, Warfield S, Kikinis R, Zientara G, Barnes PD, Volpe JJ 1999 Periventricular white matter injury in the premature infant is associated with a reduction in cerebral cortical gray matter volume at term. Ann Neurol 46:755-760

28. Cioni G, Bertuccelli B, Boldrini A, Canapicchi R, Fazzi B, Guzzetta A, Mercuri E 2000 Correlation between visual function, neurodevelopmental outcome, and magnetic resonance imaging findings in infants with periventricular leukomalacia. Arch Dis Child Fetal Neonatal Ed 82:F134-F140

29. Morrow JD, Roberts LJ 1997 The isoprostanes: unique bioactive products of lipid peroxidation. Prog Lipid Res 36:1-21

30. Nourooz-Zadeh J, Gopaul NK, Barrow S, Mallet AI, Anggard EE 1995 Analysis of $\mathrm{F}_{2}$-isoprostanes as indicators of non-enzyme lipid peroxidation in vivo by gas chromatography-mass spectrometry: development of a solid phase extraction procedure. J Chromatog B Biomed Appl 667:199-208

31. Gniwotta C, Morrow JD, Roberts LJ, Kuhn H 1997 Prostaglandin F2-like compounds, F2-isoprostanes, are present in increased amounts in human atherosclerotic lesions. Arterioscler Thromb Vasc Biol 11:3236-3241

32. Brand A, Gil S, Seger R, Yavin E 2001 Lipid constituents in oligodendroglial cells alter susceptibility to $\mathrm{H} 2 \mathrm{O} 2$-induced apoptotic cell death via ERK activation. J Neurochem 76:910-918

33. Bartnik BL, Juurlink BHJ, Devon RM 2000 Macrophages: their myelinotropic or neurotoxic actions depend upon tissue oxidative stress Mult Scler 6:37-42

34. Houdou S, Kuruta H, Hasegawa M, Konomi H, Takashima S, Suzuki Y, Hashimoto T 1991 Developmental immunohistochemistry of catalase in the human brain. Brain Res 556:267-270

35. Bagenholm, R, Nilsson UA, Kjellmar I 1997 Formation of free radicals in hypoxic ischemic brain damage in the neonatal rat, assessed by an endogenous spin trap and lipid peroxidation. Brain Res 773:132-138

36. Bagenholm R, Nilsson UA, Gotborg CW, Kiellmer I 1998 Free radicals are formed in the brain of fetal sheep during reperfusion after cerebral ischemia. Pediatr Res 43: 271-275

37. Armstead WM, Mirro R, Busjia DW, Leffler CW 1988 Postischemic generation of superoxide anion by newborn pig brain. Am J Physiol 225: H401-H403

38. Jain M, Aneja S, Mehta G 2000 CSF Interleukin-1 $\beta$, tumor necrosis factor-a and free radicals production in relation to clinical outcome in acute bacterial meningitis. Indian Pediatr 37:608-614

39. Inder TE, Mocatta T, Darlow BA, Spencer C, Winterbourn CC, Volpe JJ 2001 Elevation of oxidative injury markers in the CNS with periventricular leukomalacia in a premature infant with meningitis. J Pediatr (in press)

40. Marin-Padilla M 1997 Developmental neuropathology and impact of perinatal brain damage. II. White matter lesions of the neocortex, J Neuropathol Exp Neurol $56: 219-235$ 